\title{
Reaproveitamento de resíduo sólido proveniente do setor siderúrgico em cerâmica vermelha
}

\section{(Utilization of solid waste from siderurgical industry in red ceramic)}

\author{
G. E. Oliveira, J. N. F. Holanda \\ LAMAV-CCT, Universidade Estadual do Norte Fluminense \\ Campos dos Goytacazes, RJ, 28013-602 \\ holanda@uenf.br
}

\begin{abstract}
Resumo
Este trabalho mostra os resultados de um estudo sobre a incorporação de resíduo sólido proveniente do setor siderúrgico na formulação de uma massa argilosa utilizada na fabricação de cerâmica vermelha. As massas preparadas continham os seguintes teores de resíduo de siderurgia: $0 ; 0,5 ; 1,0 ; 1,5 ; 2,0 ; 2,5$ e 3,0\% em peso. Os resultados de difração de raios X, distribuição de tamanho de partículas e limites de Atterberg são apresentados para as massas argilosas. Os corpos-de-prova foram conformados por extrusão a vácuo e queimados nas temperaturas de $850{ }^{\circ} \mathrm{C}, 900{ }^{\circ} \mathrm{C}, 950{ }^{\circ} \mathrm{C}, 1000{ }^{\circ} \mathrm{C}$ e $1050{ }^{\circ} \mathrm{C}$. As propriedades físico-mecânicas foram determinadas em função da temperatura de queima e do conteúdo de resíduo de siderurgia. Os resultados obtidos indicaram que o resíduo sólido de siderurgia adicionado modificou as características físico-químicas e, também, as propriedades da massa argilosa pura. As massas cerâmicas contendo resíduo de siderurgia têm potencial para serem empregadas na fabricação de produtos de cerâmica vermelha para a construção civil.
\end{abstract}

Palavras-chave: resíduo sólido de siderurgia, reciclagem, cerâmica vermelha.

Abstract

This work presents the results of a study on the incorporation of solid waste from siderurgical industry in the formulation of a clayey mass used in the production of red ceramics. The prepared masses contained the following amounts of siderurgy waste: 0, 0.5, 1.0, 1.5, 2.0, 2.5 and 3.0wt\%. The results of X-ray diffraction, granulometry and Atterberg's limits are presented for the ceramic masses. Test specimens were conformed by vacuum extrusion and fired at temperatures of $850{ }^{\circ} \mathrm{C}, 900{ }^{\circ} \mathrm{C}, 950{ }^{\circ} \mathrm{C}, 1000^{\circ} \mathrm{C}$ and $1050^{\circ} \mathrm{C}$. The physical-mechanical properties were determined as a function of firing temperature and content of siderurgy waste. The results indicate that the addition of siderurgy solid waste modify the physic-chemical characteristics of the clayey mass and the ceramic properties of the test specimens. The results suggest also that the ceramic masses containing siderurgy waste could be used in the production of red ceramic for civil construction.

Keywords: siderurgy solid waste, recycling, red ceramic.

\section{INTRODUÇÃO}

No Brasil há enormes jazidas de argilas, com importância em diversas áreas, principalmente na indústria de cerâmica vermelha. Este tipo de indústria abrange a fabricação de produtos à base de argilas. Produtos tais como tijolos, blocos cerâmicos, lajotas e telhas são destinados à indústria da construção civil, compreendendo hoje cerca de 13.000 pequenas e médias unidades produtivas dispersas por todo o país [1].

O município de Campos dos Goytacazes, localizado no norte do Estado do Rio de Janeiro, apresenta, devido a suas características geológicas, grandes reservas de argilas predominantemente cauliníticas [2-4]. Atualmente o pólo ceramista instalado neste município corresponde a cerca de $35 \%$ da produção e $35 \%$ das empresas instaladas de cerâmica vermelha no Estado do Rio de Janeiro. Cerca de cento e dez unidades produtivas extraem por dia quatro mil toneladas de argilas para produzir por volta de dois milhões de peças/dia, principalmente tijolos, blocos cerâmicos, lajotas e telhas [5].

$\mathrm{Na}$ atualidade, os problemas ligados a poluição e ao descarte de resíduos industriais são de grande importância e preocupam tanto o setor industrial quanto a sociedade como um todo [6]. A indústria siderúrgica gera enormes quantidades de resíduos durante os seus processos produtivos. Alguns destes resíduos são pós de granulometria fina e ricos em óxidos de ferro [7]. O manuseio destes pós facilita a formação de névoa e poeiras dificultando a sua reutilização no processo produtivo. Assim, há necessidade de se buscar alternativas para o reaproveitamento destes resíduos de forma a não agredir o meio ambiente. Neste contexto, um setor que apresenta enorme potencial para contribuir na solução de problemas ambientais 
originados nos mais diversos processos industriais é o da cerâmica vermelha. De fato, trabalhos reportados na literatura [8-10] têm mostrado que é perfeitamente possível a reciclagem de resíduos industriais como constituintes de massas cerâmicas para fabricação de produtos cerâmicos para construção civil.

Neste trabalho foi feito um estudo voltado para a possibilidade de reaproveitamento de um resíduo sólido proveniente do setor siderúrgico, como constituinte de massa argilosa para a fabricação de produtos de cerâmica vermelha. Os principais parâmetros a serem estudados são a quantidade de resíduo de siderurgia utilizada na formulação da massa cerâmica e a temperatura final de queima dos corpos-de-prova.

\section{MATERIAIS E MÉTODOS}

Os materiais empregados neste trabalho foram: massa argilosa industrial e resíduo sólido de siderurgia. A massa argilosa é normalmente usada na fabricação de cerâmica vermelha por uma empresa da região de Campos dos Goytacazes-RJ. Já o resíduo sólido é proveniente do setor siderúrgico e apresenta-se na forma de um pó fino e de cor escura.

As composições químicas da massa argilosa industrial e do resíduo sólido de siderurgia utilizados são mostradas nas Tabelas I e II, respectivamente [11]. Análise por difração de raios $\mathrm{X}$ indicou que o resíduo de siderurgia é constituído principalmente por óxidos de ferro (magnetita e hematita). Além do mais, há indícios da presença de quartzo, calcita, mulita e argilominerais [11].

As massas cerâmicas estudadas (- 60 mesh) foram preparadas com adições de até $3 \%$ em peso de resíduo de siderurgia, conforme mostrado na Tabela III. A etapa de mistura foi feita utilizando-se um moinho de bolas de porcelana (Gardelin, modelo 1A), por um período de $15 \mathrm{~min}$. As massas

Tabela I - Composição química da argila utilizada. [Table I - Chemical composition of the clay.]

\begin{tabular}{cc}
\hline Composição & (\% em massa) \\
\hline $\mathrm{SiO}_{2}$ & 43,11 \\
\hline $\mathrm{Al}_{2} \mathrm{O}_{3}$ & 29,70 \\
\hline $\mathrm{Fe}_{2} \mathrm{O}_{3}$ & 9,38 \\
\hline $\mathrm{TiO}_{2}$ & 1,47 \\
\hline $\mathrm{K}_{2} \mathrm{O}$ & 1,45 \\
\hline $\mathrm{Na}_{2} \mathrm{O}$ & 0,53 \\
\hline $\mathrm{MgO}$ & 1,13 \\
\hline $\mathrm{CaO}$ & 0,24 \\
\hline $\mathrm{P}_{2} \mathrm{O}_{5}$ & 0,21 \\
\hline $\mathrm{Mn}_{2} \mathrm{O}_{3}$ & 0,06 \\
\hline $\mathrm{PF}$ & 12,72 \\
\hline
\end{tabular}

$P F=$ perda ao fogo
Tabela II - Composição química do resíduo de siderurgia. [Table II - Chemical composition of the siderurgy solid waste.]

\begin{tabular}{cc}
\hline Composição & \% em massa \\
\hline $\mathrm{SiO}_{2}$ & 12,41 \\
\hline $\mathrm{Al}_{2} \mathrm{O}_{3}$ & 5,48 \\
\hline $\mathrm{Fe}_{2} \mathrm{O}_{3}$ & 57,94 \\
\hline $\mathrm{TiO}_{2}$ & 0,21 \\
\hline $\mathrm{MnO}$ & 0,62 \\
\hline $\mathrm{ZnO}$ & 0,24 \\
\hline $\mathrm{K}_{2} \mathrm{O}$ & 0,63 \\
\hline $\mathrm{CaO}$ & 5,82 \\
\hline $\mathrm{SO}_{3}$ & 2,23 \\
\hline $\mathrm{PF}$ & 14,42 \\
\hline
\end{tabular}

$\mathrm{PF}=$ perda ao fogo

preparadas foram caracterizadas sob os seguintes aspectos: difração de raios X (Seifert, modelo URD 65) utilizando-se radiação $\mathrm{Cu}-\mathrm{K} \alpha$, granulometria (NBR 7181-84) [12], massa específica real dos grãos (NBR 6508-84) [13] e os limites de consistência de Atterberg (NBR 6453-84 [14] e NBR 718084 [15]). Após mistura, as massas cerâmicas foram umedecidas até atingir umidade de $35 \%$, no sentido de obter-se consistência plástica apropriada para extrusão. Em seguida as massas umedecidas foram laminadas, utilizando-se um laminador de laboratório (Verdés, modelo BR 080), no sentido de obter uma melhor homogeneização.

Os corpos-de-prova foram conformados por extrusão a vácuo, utilizando-se uma extrusora de laboratório com boquilha de seção retangular (Verdés, modelo BR 051). A extrusão dos corpos-de-prova foi realizada sob vácuo da ordem de $680 \mathrm{mmHg}$ e pressão de saída das massas de cerca de $100 \mathrm{kPa}$. Os corpos-de-prova obtidos $\left(110 \times 28 \times 18 \mathrm{~mm}^{3}\right)$ foram secados em estufa em $110^{\circ} \mathrm{C}$ por $24 \mathrm{~h}$. As seguintes propriedades após a secagem foram determinadas: retração linear, massa

Tabela III - Composição das massas cerâmicas (\% em peso). [Table III - Compositions of the ceramic masses (wt.\%).].

\begin{tabular}{ccc}
\hline Massas & Argila & Resíduo \\
\hline C00 & 100 & 0,0 \\
\hline C05 & 99,5 & 0,5 \\
\hline C10 & 99,0 & 1,0 \\
\hline C15 & 98,5 & 1,5 \\
\hline C20 & 98,0 & 2,0 \\
\hline C25 & 97,5 & 2,5 \\
\hline C30 & 97,0 & 3,0 \\
\hline
\end{tabular}


específica aparente e tensão de ruptura à flexão com carregamento de três pontos. A queima foi realizada num forno elétrico tipo mufla (Brasimet, modelo K150), com os corposde-prova sendo mantidos na temperatura de patamar por $2 \mathrm{~h}$. A taxa de aquecimento foi de $1{ }^{\circ} \mathrm{C} / \mathrm{min}$ da temperatura ambiente $\left(\sim 30{ }^{\circ} \mathrm{C}\right)$ até a temperatura de patamar. As temperaturas de patamar utilizadas foram: $850{ }^{\circ} \mathrm{C}, 900{ }^{\circ} \mathrm{C}$, $950{ }^{\circ} \mathrm{C}, 1000{ }^{\circ} \mathrm{C}$ e $1050{ }^{\circ} \mathrm{C}$. O resfriamento foi realizado por inércia térmica, apenas desligando-se o forno e mantendo o mesmo fechado até atingir-se a temperatura ambiente. As seguintes propriedades após a queima foram determinadas: retração linear [16], absorção de água [17], massa específica aparente [17], porosidade aparente [17] e tensão de ruptura à flexão com carregamento de três pontos [18]. Foram empregados seis corpos-de-prova para as medidas das propriedades do material a verde e do material queimado.

\section{RESULTADOS E DISCUSSÃO}

A Fig. 1 mostra os difratogramas de raios $\mathrm{X}$ obtidos para as massas cerâmicas contendo diferentes conteúdos de resíduo de siderurgia. Para efeito de comparação, é mostrado também o difratograma de raios $\mathrm{X}$ da massa argilosa pura isenta de resíduo. Nota-se a presença de picos característicos dos argilominerais caulinita e ilita/mica, com predominância da caulinita $\left(\mathrm{Al}_{2} \mathrm{O}_{3} \cdot 2 \mathrm{SiO}_{2} \cdot 2 \mathrm{H}_{2} \mathrm{O}\right)$. Além disso, foram detectados picos característicos de quartzo $\left(\mathrm{SiO}_{2}\right)$, gibsita $\left(\mathrm{Al}_{2} \mathrm{O}_{3} \cdot 3 \mathrm{H}_{2} \mathrm{O}\right)$ e goetita $\left(\mathrm{Fe}_{2} \mathrm{O}_{3} \cdot \mathrm{H}_{2} \mathrm{O}\right)$. A presença de gibsita, comum em argilas da região de Campos dos Goytacazes-RJ, é indicativo de que parte do $\mathrm{Al}_{2} \mathrm{O}_{3}$ presente nas amostras (Tabela I) não está na forma ligada a estrutura do silicato [18]. Já a presença de goetita é devidamente justificada quando relacionada ao elevado conteúdo de óxido de ferro na massa argilosa. Foi detectada, também, a presença de feldspato potássico, provavelmente, em quantidade muito pequena nas massas cerâmicas. Os resultados mostram também que a incorporação

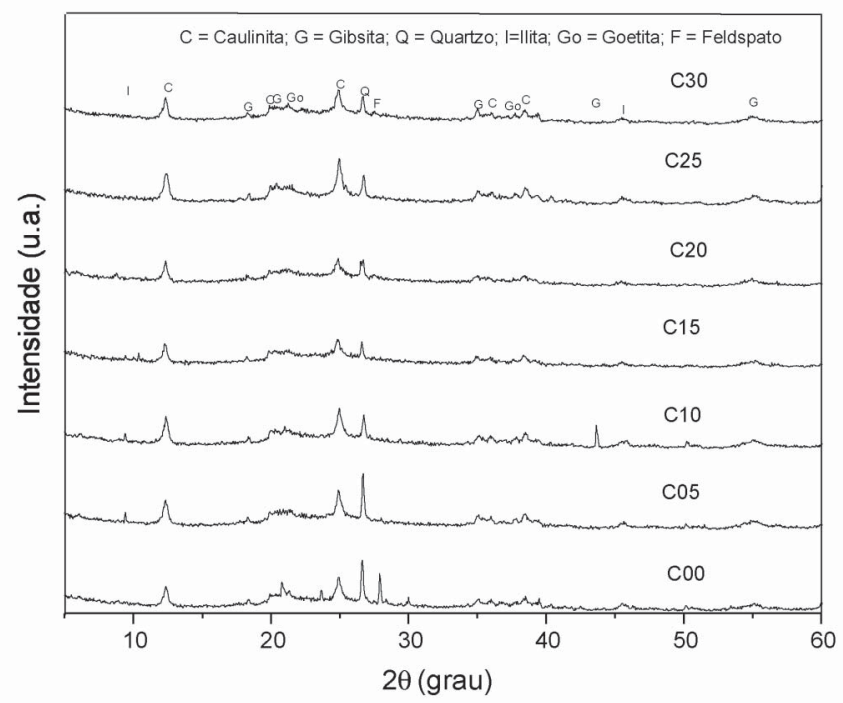

Figura 1: Difratogramas de raios $X$ das massas cerâmicas. [Figure 1: X-ray diffraction patterns of the ceramic masses.] do resíduo sólido de siderurgia provocou pequenas alterações nas intensidades de alguns picos característicos. Além disso, não foi possível identificar com clareza a presença de magnetita e hematita que são os constituintes principais do resíduo. Isto provavelmente deve-se a pequena quantidade de resíduo adicionado de no máximo 3\% em peso.

Tabela IV - Distribuição de tamanho de partículas das massas cerâmicas preparadas com adição de resíduo sólido de siderurgia.

[Table IV - Particle size distribution of the ceramic masses prepared by adding siderurgy solid waste.].

\begin{tabular}{ccccc}
\hline $\begin{array}{c}\text { Massa } \\
\text { Cerâmica }\end{array}$ & $\begin{array}{c}\text { Argila, } \% \\
(<2 \mu \mathrm{m})\end{array}$ & $\begin{array}{c}\text { Silte, } \% \\
(2 \leq \phi \\
\leq 60 \mu \mathrm{m})\end{array}$ & $\begin{array}{c}\text { Areia, } \% \\
(60 \leq \phi \\
\leq 1000 \mu \mathrm{m})\end{array}$ & $\begin{array}{c}\rho \\
\mathrm{g} / \mathrm{cm}^{3}\end{array}$ \\
\hline $\mathrm{C} 00$ & 35 & 46 & 19 & 2,71 \\
\hline $\mathrm{C} 05$ & 39 & 53 & 8 & 2,65 \\
\hline $\mathrm{C} 10$ & 38 & 56 & 6 & 2,68 \\
\hline $\mathrm{C} 15$ & 41 & 49 & 10 & 2,67 \\
\hline $\mathrm{C} 20$ & 38 & 53 & 9 & 2,68 \\
\hline $\mathrm{C} 25$ & 40 & 50 & 10 & 2,68 \\
\hline $\mathrm{C} 30$ & 39 & 51 & 10 & 2,68 \\
\hline \hline
\end{tabular}

$\rho=$ massa especifica real dos grãos

A distribuição de tamanho de partículas e massa específica real dos grãos são apresentadas na Tabela IV. Os dados para a massa argilosa pura também são mostrados, para efeito de comparação. As massas cerâmicas consistem de um material com partículas na faixa compreendida entre 1 e $400 \mu \mathrm{m}$. Observa-se que a granulometria da massa argilosa pura é modificada à medida que se adiciona resíduo. A fração argila

Tabela V - Limites de consistência de Atterberg para as massas cerâmicas.

[Table V - Atterberg's consistence limits for the ceramic masses.].

\begin{tabular}{lccc}
\hline $\begin{array}{c}\text { Massa } \\
\text { Cerâmica }\end{array}$ & $\begin{array}{c}\text { Limite de } \\
\text { Liquidez }\end{array}$ & $\begin{array}{c}\text { Limite de } \\
\text { Plasticidade }\end{array}$ & $\begin{array}{c}\text { Índice de } \\
\text { Plasticidade }\end{array}$ \\
\hline C00 & $(\%)$ & $(\%)$ & $(\%)$ \\
\hline C05 & 59 & 29 & 30 \\
\hline C10 & 59 & 28 & 31 \\
\hline C15 & 57 & 28 & 29 \\
\hline C20 & 53 & 27 & 27 \\
\hline C25 & 51 & 28 & 25 \\
\hline C30 & 50 & 26 & 25 \\
\hline & & 25 & 25 \\
\hline
\end{tabular}


variou de 35 até $41 \%$, a fração silte de 46 até $56 \%$, e a fração areia de 6 até $19 \%$. De modo que os conteúdos das frações argila e silte aumentaram com concomitante diminuição da fração areia. A massa específica real dos grãos diminuiu para adição de $0,5 \%$ de resíduo de siderurgia. A partir de então, a adição de mais resíduo praticamente não altera os valores de massa específica real.

$\mathrm{Na}$ Tabela $\mathrm{V}$ encontram-se os limites de consistência de Atterberg obtidos para as massas estudadas. Pode-se observar que o resíduo de siderurgia adicionado tende a diminuir os limites de consistência de Atterberg. Ainda assim, todas as massas cerâmicas encontram-se na faixa apropriada a moldagem por extrusão, cujo índice de plasticidade está compreendido entre 10-35\% [4]. Devido ao comportamento não plástico do resíduo, os ensaios para determinação das propriedades plásticas baseados nas normas NBR 6459/84 e NBR 7180/84 foram impraticáveis por causa da natureza não coesiva do resíduo. As massas cerâmicas argilosas contendo até 3\% em peso de resíduo de siderurgia, sob o ponto de vista da mecânica dos solos, podem ser classificadas como pertencentes ao grupo das argilas inorgânicas de alta plasticidade [20].

Tabela VI - Propriedades dos corpos-de-prova secados a $110{ }^{\circ} \mathrm{C}$. [Table VI - Properties of the ceramic bodies in the dried state at $110^{\circ} \mathrm{C}$.].

\begin{tabular}{cccc}
\hline $\begin{array}{c}\text { Massa } \\
\text { Cerâmica }\end{array}$ & $\mathrm{RL}_{\mathrm{s}}(\%)$ & $\mathrm{D}_{\mathrm{a}}\left(\mathrm{g} / \mathrm{cm}^{3}\right)$ & $\sigma_{\mathrm{s}}(\mathrm{MPa})$ \\
\hline $\mathrm{C} 00$ & $6,37 \pm 0,28$ & $1,67 \pm 0,01$ & $2,71 \pm 0,31$ \\
\hline $\mathrm{C} 05$ & $6,33 \pm 0,45$ & $1,63 \pm 0,02$ & $3,04 \pm 0,20$ \\
\hline $\mathrm{C} 10$ & $6,73 \pm 0,17$ & $1,66 \pm 0,01$ & $2,98 \pm 0,16$ \\
\hline $\mathrm{C} 15$ & $7,58 \pm 0,07$ & $1,64 \pm 0,02$ & $2,54 \pm 0,20$ \\
\hline $\mathrm{C} 20$ & $7,54 \pm 0,34$ & $1,63 \pm 0,01$ & $2,50 \pm 0,20$ \\
\hline $\mathrm{C} 25$ & $7,34 \pm 0,29$ & $1,60 \pm 0,02$ & $2,42 \pm 0,17$ \\
\hline $\mathrm{C} 30$ & $7,96 \pm 0,43$ & $1,58 \pm 0,02$ & $2,32 \pm 0,15$ \\
\hline
\end{tabular}

A Tabela VI mostra os resultados obtidos para as propriedades de retração linear $\left(\mathrm{RL}_{\mathrm{s}}\right)$, massa específica aparente $\left(\mathrm{D}_{\mathrm{a}}\right)$ e tensão de ruptura à flexão $\left(\sigma_{\mathrm{s}}\right)$, para os corposde-prova secados em $110^{\circ} \mathrm{C}$. Nota-se que ocorreram pequenas variações nos valores destas propriedades de secagem com a adição do resíduo sólido de siderurgia. Os valores de retração linear de secagem dos corpos-de-prova obtidos estão compreendidos dentro da faixa de 6,33 até $7,96 \%$. Estes valores estão dentro dos limites apropriados para fabricação de cerâmica vermelha [21]. A retração linear dos corpos-de-prova tende a aumentar levemente com a adição do resíduo. Já a massa específica aparente tende a diminuir suavemente com a adição de resíduo. Isto provavelmente está relacionado a natureza não plástica do resíduo. Os valores de tensão de ruptura de secagem obtidos estão compreendidos dentro da faixa adequada $(0,5-7,0 \mathrm{MPa})$ para fabricação de cerâmica

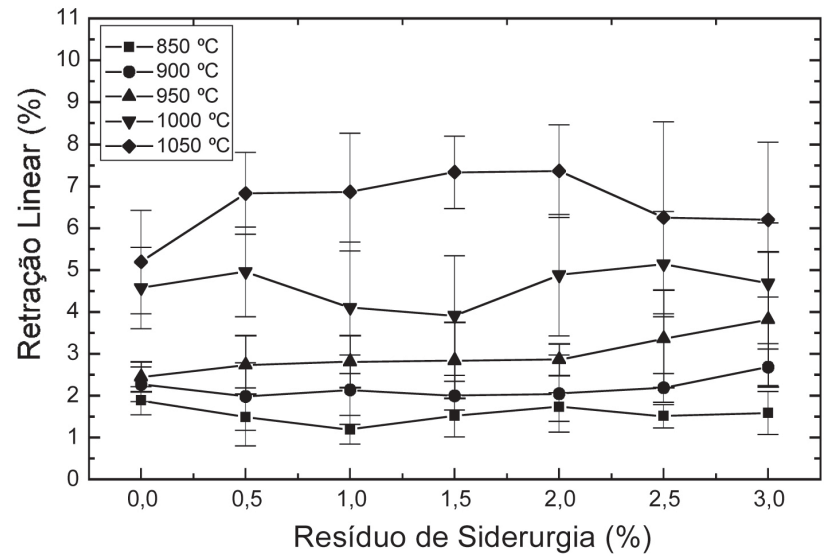

Figura 2: Retração linear em função do conteúdo de resíduo de siderurgia e da temperatura de queima.

[Figure 2: Linear shrinkage as a function of siderurgy waste content for all firing temperatures.]

estrutural [21,22]. Inicialmente ocorreu um leve aumento com adição de $0,5 \%$ de resíduo. A partir de então, a adição de mais resíduo tende a diminuir a tensão de ruptura dos corpos-deprova. As modificações observadas, indicam que a adição do resíduo torna os corpos-de-prova secos menos densos e menos resistentes, exigindo cuidados no manuseio.

De modo geral, as propriedades físico-mecânicas são influenciadas, tanto pelo resíduo de siderurgia quanto pela temperatura de queima. Entretanto, o efeito da temperatura é mais acentuado.

A Fig. 2 mostra a retração linear dos corpos-de-prova em função do percentual do resíduo e da temperatura de queima. Os valores de retração linear compreendidos na faixa de 1,19 até 7,33\%, mostraram-se satisfatórios para as temperaturas empregadas. Em geral, observa-se que o comportamento da retração linear é complexo, mas com uma leve tendência de queda nos valores de retração linear. Apesar de pouco significativa, a razão para isto pode estar relacionado com as

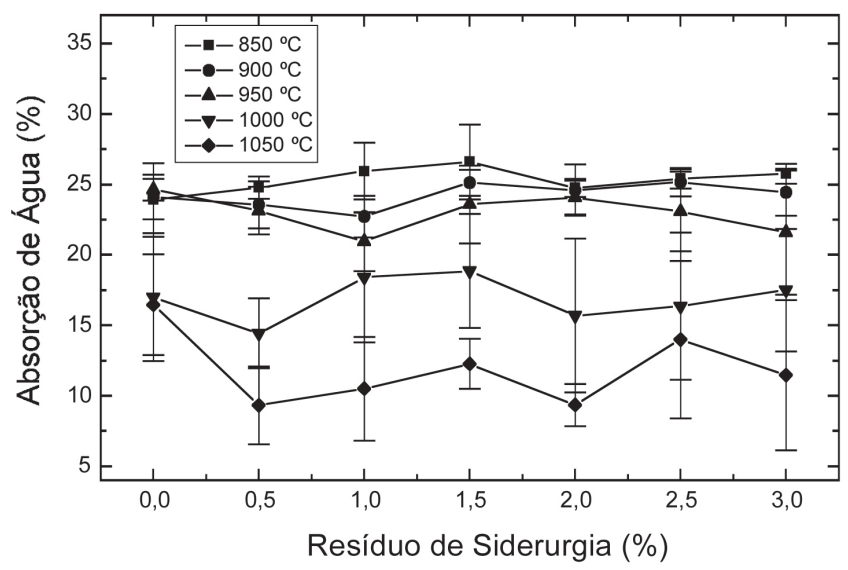

Figura 3: Absorção de água em função do conteúdo de resíduo de siderurgia e da temperatura de queima.

[Figure 3: Water absorption as a function of siderurgy waste content for all firing temperatures.]. 


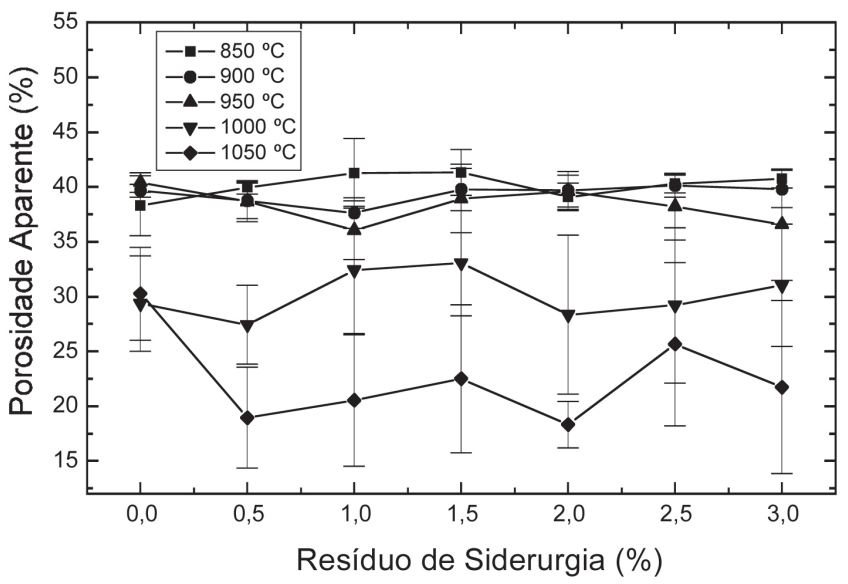

Figura 4: Porosidade aparente em função do conteúdo de resíduo de siderurgia e da temperatura de queima.

[Figure 4: Apparent porosity as a function of siderurgy waste content for all temperatures.].

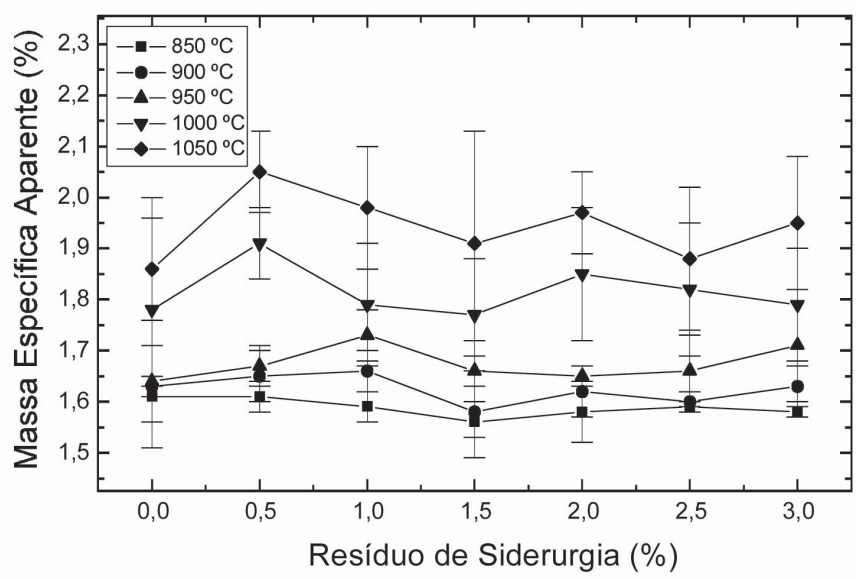

Figura 5: Massa específica aparente em função do conteúdo de resíduo de siderurgia e da temperatura de queima.

[Figure 5: Apparent density as a function of siderurgy waste content for all firing temperatures.]

modificações químico-mineralógica que a massa argilosa pura sofreu com a incorporação de um material não plástico, como o resíduo sólido de siderurgia. Pode-se observar, também, que a temperatura de queima afeta significativamente a retração linear dos corpos-de-prova. Quanto maior for a temperatura, maior é a retração linear. O efeito da temperatura fica mais evidente principalmente a partir da temperatura de $1000{ }^{\circ} \mathrm{C}$, na qual são obtidos os maiores valores de retração linear. Isto deve-se ao maior grau de vitrificação (formação de fase vítrea), que contribuiu para maior densificação dos corpos-de-prova.

Os valores de absorção de água dos corpos-de-prova contendo diferentes conteúdos de resíduo de siderurgia e queimados a diferentes temperaturas, são mostrados na Fig. 3. Nota-se nesta figura que a adição de resíduo de siderurgia não provocou influência significativa na absorção de água dos corpos-de-prova até a temperatura de $950{ }^{\circ} \mathrm{C}$. A partir de então, a absorção de água apresenta uma variação complexa

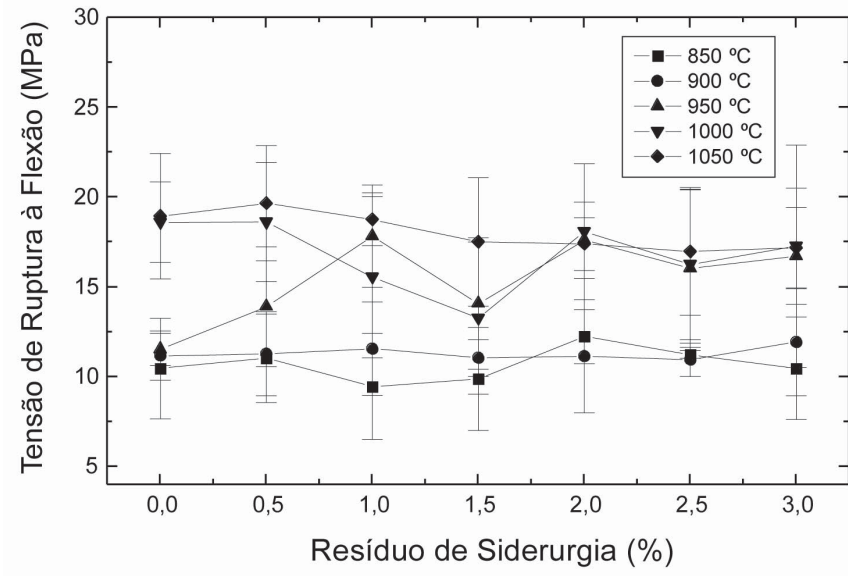

Figura 6: Tensão de ruptura à flexão em função do conteúdo de resíduo de siderurgia e da temperatura de queima.

[Figure 6: Flexural strength as a function of siderurgy waste content for all firing temperatures.].

com a adição do resíduo. Contudo, a temperatura influenciou fortemente a absorção de água, principalmente nas temperaturas mais elevadas. Entre 850 e $950{ }^{\circ} \mathrm{C}$ ocorreu somente uma leve queda nos valores de absorção de água. Nesta faixa de temperatura a sinterização é dominada principalmente pelo maior contato partícula-partícula, principalmente das placas de metacaulinita oriundas da massa argilosa. Já acima de $950^{\circ} \mathrm{C}$ encontram-se os menores valores de absorção de água e, portanto, da porosidade aberta dos corpos-de-prova. Tal comportamento deve-se a formação de uma maior quantidade de fase vítrea, com provável sinterização por fluxo viscoso [4]. Os resultados obtidos para a porosidade aparente (Fig. 4) e massa específica aparente (Fig. 5) corroboram o comportamento observado para a absorção de água.

A tensão de ruptura à flexão dos corpos-de-prova como uma função do percentual de resíduo e temperatura de queima é mostrado na Fig. 6. Observa-se que a tensão de ruptura aumentou com o aumento da temperatura de queima. E de modo similar ao observado para as demais propriedades, este aumento está relacionado a maior densificação dos corposde-prova, principalmente acima de $950{ }^{\circ} \mathrm{C}$. Os resultados também sugerem que há uma boa correlação entre os valores de tensão de ruptura á flexão (Fig. 6) e absorção de água (Fig. 3). Já o comportamento da tensão de ruptura à flexão em função do percentual de resíduo adicionado é complexo, como verificado para as demais propriedades. Para temperaturas até $900{ }^{\circ} \mathrm{C}$, ocorreu uma pequena variação nos valores de tensão de ruptura em função do percentual de resíduo de siderurgia. Já para temperaturas entre $950{ }^{\circ} \mathrm{C}$ e $1050{ }^{\circ} \mathrm{C}$, a variação da tensão de ruptura foi mais expressiva, porém complexa. Entretanto, é difícil inferir uma tendência de comportamento. Isto é decorrente do pequeno lote utilizado, seis corpos-deprova por composição, assim como da grande dispersão dos valores de tensão de ruptura à flexão observados, onde as barras de erros (um desvio padrão) refletem esses fatos. 
A absorção de água (AA) e a resistência mecânica ( $\sigma$ ) são propriedades importantes neste trabalho, pois as mesmas são geralmente utilizadas para classificar materiais à base de argilas para fabricação de produtos de cerâmica vermelha para uso na construção civil. Os valores especificados destas propriedades para cerâmica vermelha são [23]: tijolos maciços (AA $<25 \%$ e $\sigma>2,0 \mathrm{MPa}$ ), blocos cerâmicos (AA $<25 \%$ e $\sigma>5,5 \mathrm{MPa}$ ) e telhas (AA $<20 \%$ e $\sigma \geq 6,5 \mathrm{MPa}$ ). As especificações para tijolos maciços e blocos cerâmicos foram atingidas em todas as temperaturas de queima testadas. Já as especificações para telha foram atingidas somente acima de $950^{\circ} \mathrm{C}$.

Outro critério importante usado para classificação de uma massa argilosa para fabricação de produtos de cerâmica vermelha é a sua cor de queima [22]. Os corpos-de-prova contendo até $3 \%$ em peso de resíduo sólido de siderurgia tendem a apresentar cor de queima avermelhada e, portanto, apropriada para este tipo de aplicação.

\section{CONCLUSÕES}

As massas cerâmicas preparadas com adições de até 3\% em peso de resíduo sólido de siderurgia são mineralogicamente de predominância caulinítica. As características das massas cerâmicas estudadas são alteradas com a adição deste tipo de resíduo, onde ocorreu um aumento das frações argila e silte e diminuição da fração areia. O resíduo adicionado contribuiu para a redução das propriedades plásticas das massas cerâmicas, indicando que o mesmo constitui-se num material não plástico. As propriedades físico-mecânicas são influenciadas pela temperatura de queima. $\mathrm{O}$ efeito da temperatura de queima é mais pronunciado, principalmente, acima de $950{ }^{\circ} \mathrm{C}$ devido ao maior grau de sinterização dos corpos cerâmicos. Por outro lado, essas propriedades como uma função do conteúdo de resíduo de siderurgia adicionado apresentaram uma variação complexa, dificultando inferir uma tendência clara de comportamento. Apesar disso, os resultados obtidos demonstram claramente que o resíduo sólido de siderurgia pode ser, perfeitamente, reaproveitado como constituinte de massas cerâmicas para fabricação de produtos de cerâmica vermelha tais como tijolos maciços, blocos cerâmicos e telhas, empregados na construção civil. A cor de queima dos corpos-de-prova também é adequada para uso em cerâmica vermelha.

\section{AGRADECIMENTOS}

Os autores agradecem a Cerâmica São José pelo fornecimento das matérias-primas utilizadas e a FAPERJ pelo apoio financeiro parcial para a realização deste trabalho.

\section{REFERÊNCIAS}

[1] Associação Brasileira de Cerâmica, www.abceram.org.br (2002).

[2] J. N. F. Holanda, G. P. Souza, Anais do $43^{\circ}$ Congresso Brasileiro de Cerâmica, Florianópolis, SC (1999) 8201-8210.

[3] J. Alexandre, F. Saboya, B. C. Marques, M. L. P. Ribeiro, C. Salles, M. G. Silva, M. S. Sthel, L. T. Auler, H. Vargas, Analyst 124 (1999) 1209.

[4] C. M. F. Vieira, J. N. F. Holanda, D. G. Pinatti, Cerâmica 46, 297 (2000) 15.

[5] J. N. F. Holanda, C. M. F. Vieira, Mundo Cerâmico 82 (2002) 29.

[6] J. Szekely, J. Trapaga, J. Mater. Res. 10, 9 (1995) 2178.

[7] N. Ortiz, M. A. F. Pires, M. S. Casola, Anais do $41^{\circ}$ Congresso Brasileiro de Cerâmica, Vol. II, S. Paulo, SP (1997) 721-724.

[8] E. A. Domingues, R. Ullmann, Appl. Clay Sci. 11 (1996) 237. [9] V. M. John, S. E. Zorban, Waste Management 21, 3 (2001) 213. [10] R. R. Menezes, H. S. Ferreira, G. A. Neves, H. C. Ferreira, Cerâmica 48, 306 (2002) 92.

[11] G. E. Oliveira, Dissertação de Mestrado, Universidade Estadual do Norte Fluminense, CCT-LAMAV, Campos dos Goytacazes, RJ (2002).

[12] ABNT, NBR 7181-84, Solo: Análise Granulométrica (1984).

[13] ABNT, NBR 6508-84, Solo: Massa Específica Real dos Grânulos (1984).

[14] ABNT, NBR 6453-84, Solo: Determinação do Limite de Liquidez (1984).

[15] ABNT, NBR 7180-84, Solo: Determinação do Limite de Plasticidade (1984).

[16] ABNT, NBR MB 305, Determinação da Retração Linear (1984).

[17] ASTM, C 378-88, Test Method for Water Absorption, Bulk Density, Apparent Porosity and Apparent Specific Gravity of Fired Whiteware Products (1988).

[18] ASTM, C 674-77, Flexural Properties of Ceramic Whiteware Materials (1977).

[19] G. P. Souza, R. Sanchez, J. N. F. Holanda, Cerâmica 48, 306 (2002) 102.

[20] L. F. A. Campos, R. S. Macedo, P. K. Kiyohara, H. C. Ferreira, Cerâmica 45, 295 (1999) 144.

[21] L. Barzaghi, A. Salge, Cerâmica 28, 151 (1982) 291.

[22] P. S. Santos, Ciência e Tecnologia de Argilas, Vol. 1, $2^{\text {a }}$ Ed., Edgard Blücher Ltda., S. Paulo (1989).

[23] Pólo Produções, Anuário Brasileiro de Cerâmica Vermelha, Ed: J. L. Francisco, Criciúma, SC (2000) 36.

(Rec. 15/08/02, Rev. 14/10/03, Ac. 27/02/04) 